\title{
Iran's Health System Transformation Plan: A SWOT analysis
}

\author{
Alireza Olyaeemanesh ${ }^{1}$, Masoud Behzadifar*2, Nasrin Mousavinejhad ${ }^{3}$, Meysam Behzadifar, ${ }^{3,4}$, \\ Sanaz Heydarvand ${ }^{5}$, Samad Azari ${ }^{2}$, Mariano Martini ${ }^{6}$, Ahad Bakhtiari ${ }^{7}$, Nicola Luigi Bragazzi ${ }^{8}$
}

Received: 27 Sep 2017

Published: 12 May 2018

\begin{abstract}
Background: Societies are characterized by evolving health needs, which become more challenging throughout time, to which health system should respond. As such, a constant monitoring and a periodic review and reformation of healthcare systems are of fundamental importance to increase the efficiency and effectiveness of healthcare services delivery, equity, and sustainable funding. The establishment of President Rouhani's government in Iran, on May 5, 2014, the settlement of the new Ministry of Health and Medical Education administration (MoHME) and the need for change in the provision of healthcare services has led to the "Health System Transformation Plan" (HSTP). The aim of the current investigation was to critically evaluate the health transformation plan in Iran.

Methods: Strengths, Weaknesses, Opportunities and Threats (SWOT) analysis enables to identify and assess the strengths and weaknesses within an organization or program, as well as the threats and opportunities outside the given organization or program. To identify SWOT of the HSTP in Iran, all articles concerning this program published in scholarly databases as well as in the gray literature were systematically searched. Subsequently, all factors identified at the first round were thematically classified into four categories and for reaching consensus on this classification, the list of points and factors was sent to 40 experts - policy- and decisionmakers, professors and academicians, health department workers, health activists, journalists.

Results: Thirty-four subjects expressed comments on classification. Incorporating their suggestions, the SWOT analysis of Iran's HSTP was revised, finalized and then performed.

Conclusion: HSTP in Iran, like many of the initiatives that have been recently introduced and not fully implemented, have various challenges, difficulties and pitfalls that health policymakers need to pay attention to. Interacting with criticisms, taking into account public opinion and strengthening the plan can make the project more effective, and it can be anticipated that in the future, better conditions in the health sector will be achieved.
\end{abstract}

Keywords: Strengths, Weaknesses, Opportunities, Threats, SWOT, Health system transformation plan, Iran

Copyright $\odot$ Iran University of Medical Sciences

Cite this article as: Olyaeemanesh A, Behzadifar M, Mousavinejhad N, Behzadifar M, Heydarvand S, Azari S, Martini M, Bakhtiari A, Luigi Bragazzi N. Iran's Health System Transformation Plan: A SWOT analysis. Med J Islam Repub Iran. $2018(12$ May);32:39. https://doi.org/10.14196/mjiri.32.39

\section{Introduction}

Societies are characterized by evolving needs, including health, which continuously become more complex, multifaceted and challenging throughout time, to which public systems, and, in particular, health system should respond.

Corresponding author: Dr Masoud Behzadifar, masoudbehzadifar@gmail.com

1. National Institute for Health Research, Tehran University of Medical Sciences, Tehran, Iran.

2. Health Management and Economics Research Center, Iran University of Medical Sciences, Tehran, Iran.

3. Social Determinants of Health Research Center, Lorestan University of Medical Sciences, Khorramabad, Iran.

4. Department of Epidemiology, Faculty of Health and Nutrition, Lorestan University of Medical Sciences, Khorramabad, Iran.

5. Bahrami Pediatric Hospital, Tehran University of Medical Sciences, Tehran, Iran.

6. Postgraduate School of Public Health, Department of Health Sciences (DISSAL), University of Genoa, Genoa, Italy.

7. Department of Health Economics and Management, School of Public Health, Tehran University of Medical Sciences, Tehran, Iran.

8. Department of Health Sciences (DISSAL), Section of History of Medicine and Ethics, University of Genoa, Genoa, Italy.
As such, a constant monitoring and a periodic review and reformation of health systems are of fundamental importance in all countries of the world, in order to increase the efficiency and effectiveness of healthcare services

\section{$\uparrow$ What is "already known" in this topic:}

Societies are characterized by evolving needs, including health, which become more complex, multifaceted and challenging throughout time. As such, a constant monitoring and a periodic review and reformation of health systems are of fundamental importance in all countries of the world.

\section{$\rightarrow$ What this article adds:}

The current analysis enabled us to individuate the main strengths, weaknesses, opportunities and threats of Iran's health transformation plan (HSTP). HSTP in Iran presents challenges, difficulties and pitfalls that health policy- and decision-makers need to pay attention to. Taking into account experts' controversies as well as public opinion and strengthening the plan can make the project more effective, and it can be anticipated that, in the future, better health conditions will be achieved. 
delivery, quality, equity, and sustainable financing (1).

The World Health Organization (WHO) defines reform as remarkable efforts with specific goals aimed at improving the performance of the health system, which promote countries to regularly review policies and processes (2). Healthcare systems have undergone several reforms in many countries, and health policy- and decision-makers have tried to pursue specific goals (3-5). Different countries have changed their healthcare systems to respond to challenges of the time and to improve their health-related processes, and have also made good progress in this regard, in particular concerning health promotion. However, not all of these reforms have been equally successful in achieving their objectives (5-7).

The establishment of President Rouhani's government in Iran, on May 5, 2014, the settlement of the new Ministry of Health and Medical Education (MoHME) and the need for change in the provision of healthcare services have led to the "Health System Transformation Plan" (HSTP) (8). HSTP in treatment section includes a rather articulated package comprising eight healthcare services, measures and interventions: the most important interventions were the program aimed at reducing the rate of co-payment for hospitalized patients in hospitals affiliated with the MoHME as well as providing all necessary medicines, consumables and services inside the hospitals; the program aimed at redistributing doctors in hospitals situated in less developed areas, with incentives for encouraging them to stay and work in deprived territories, in order to increase equity in accessing to healthcare services and reducing the disparity between the different areas of the country. Furthermore, these programs were aimed at increasing the presence of specialist physicians residing in hospitals affiliated with the MoHME, improving the quality of visiting services as well as of hoteling in hospitals affiliated with the MoHME, and revising and updating the health services tariffs to more realistic values. There has been a transformation plan in primary health care (PHC) and prevention section which is not, however, the major focus of this paper.

On the other hand, every health plan has its own strengths and weaknesses. During the many stages of the implementation of the health system reform plan, policyand decision-makers should take into proper account the needs, the requests and the observations of the different stakeholders, in such a way to share the decision-making processes and to make an effective healthcare reform. Besides involving the stakeholders, another important and vital point is to critically review, analyze and appraise the reform plan (2). The implementation of HSTP in Iran has undoubtedly a number of weaknesses that should be properly recognized and addressed. After the implementation of the plan, policy- and decision-makers, health professionals, managers, mass media, health sector activists, and university scholars raised a number of different observations. The aim of the current investigation is to critically evaluate the HSTP in Iran.

\section{Methods}

Strengths, Weaknesses, Opportunities and Threats (SWOT) analysis enable to identify and assess the strengths and weaknesses within an organization or program, as well as the threats and opportunities outside the given organization or program. This should increase its strengths and reduce its weaknesses, also take advantage of opportunities outside itself and avoid them as much as possible, or, at least, contain the risks.

On the other hand, SWOT is a subjective tool in which factors are classified into four categories: strength, weakness, opportunity, and threat, and merely provides an analysis and, as such, cannot be a measurement tool (9). To accomplish our SWOT analysis of Iran's healthcare transformation plan concerning health promotion, we designed and implemented two steps namely, round 1 and round 2

\section{Round 1}

To identify the SWOTs of the health promotion plan in Iran, all articles concerning this program published in scholarly databases, such as ISI/Web of Science, Embase, PubMed/MEDLINE, Scopus, Google Scholar, as well as Iranian thesauri, like MagIran, Irandoc, and SID were systematically searched using a proper string of keywords such as "health policy", "health reform", and "Iran". Also, gray literature was searched: more in details, all conferences, congresses, proceedings, interviews, news and social sites reports in which political and health-related issues were discussed.

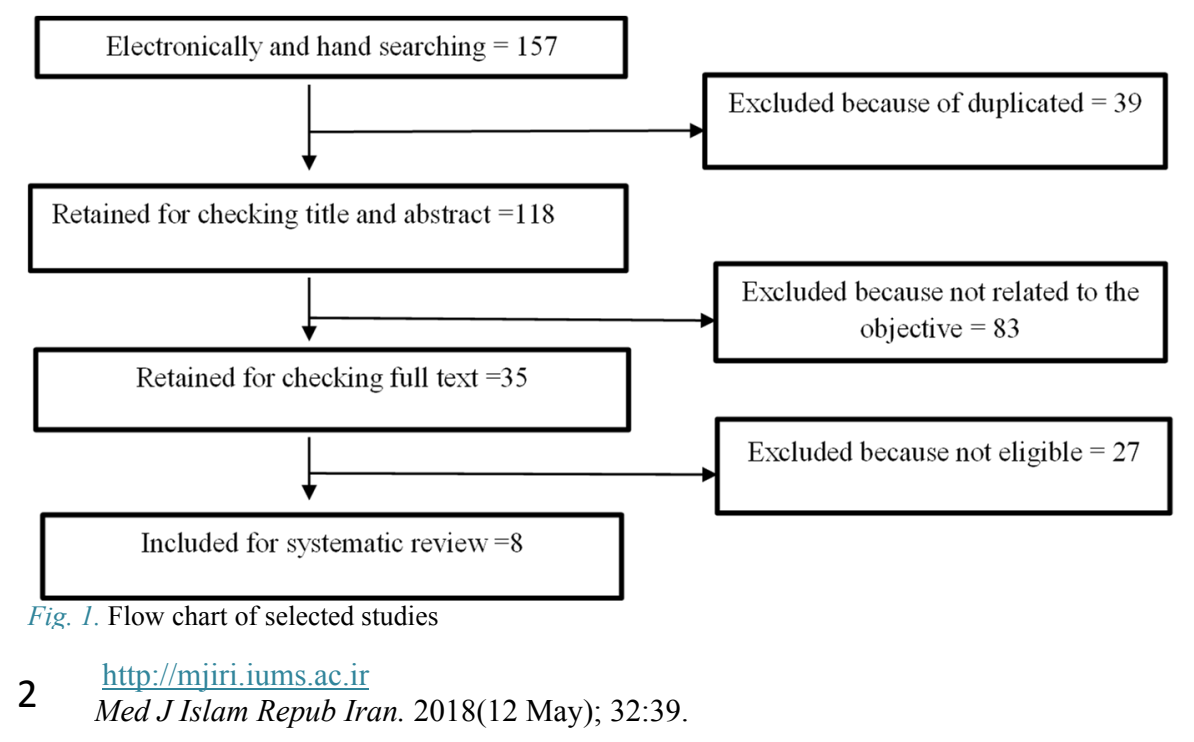


To systematically search for studies, the following search strategies were adopted using a proper list of keywords connected by Boolean operators (AND, OR, NOT): namely, ("Health Sector Transformation Plan" OR "Health reform plan" OR "Healthcare Overhaul Plan" OR "Health development plan" OR "Health system transformation" OR "Health system transformation program" AND "Iran"). Persian keywords were also used for searching in Persian databases. Studies that highlighted SWOT of the healthcare project were selected. Fig. 1 shows the process of finding and searching for relevant studies. The "Critical Appraisal Skills Programme" (CASP) checklist was used in order to assess the quality of the studies. According to the studies retained at this stage, a list of all SWOT indices was created. The list was then reviewed by ten people (experts and academic staff in the field of health) and, based on their views and expertise, SWOTrelated subgroups were created. Participants in this round set the factors up to saturation for each of the four SWOT domains.

\section{Round 2}

The snowball method was used to select the participants. In this method, after interviewing the people, they were asked to introduce other people who had good information in this field. To collect data at this stage, the list prepared in the first round was sent by e-mail to the participants. In the e-mail, individuals were asked to prioritize factors based on their opinions. We tried to use a homogeneous method ensuring at the same time maximum diversity in selecting participants.

At this stage, factors identified at the first round were thematically classified into four categories (namely, political, economic, social and cultural). After classification, for reaching related consensus a list of points and factors was sent to 40 experts - policy- and decision-makers, professors and academicians, health department workers, health activists and journalists by e-mail. Since this information was obtained via snowballing, it could not be representative of the Iranian academic, political and professional worlds. After receiving their feedbacks and obser- vations, the final classification was reformulated and set up. At this stage, factors were ranked according to the participants' comments (Table 1). Individuals were asked to prioritize factors based on their opinions. In an e-mail sent to the participants, they were provided with explanations of the research objectives and we assured them that their comments would remain reserved and confidential, being known only by the researchers.

\section{Study period}

This was study conducted between January 2017 and May 2017.

\section{Results}

Thirty-four participants expressed comments on classification (participation rate $85.0 \%$ ). Incorporating their suggestions, the SWOT analysis of Iran's HSTP is presented below.

\section{Strengths}

Strengths of the Iran's health transformation plan (Table 1) are given by increasing the presence of specialist physicians and improving the delivery to the public of highquality healthcare service (in particular, strengthening emergency services and establishing airline's emergency services, as well as opening new hospitals and modernizing the equipments). The implementation of standardized protocols, based on available scientific evidences, the exploitation of new technologies (such as e-health records) for reducing costs and the use of the Health Technology Assessment (HTA) tool for effectively allocating resources, which have contributed to the delivery of more appropriate healthcare services, reducing the number of cesarean sections and favoring vaginal delivery and decreasing the referrals of patients to medical care provided outside the hospitals, represent other strengths of the HSTP.

Furthermore, reviewing healthcare tariffs, improving the time of visit, reducing out-of-pocket expenditure and informal payments, creating incentives for healthcare workers, paying attention to the marginalization of underdevel-

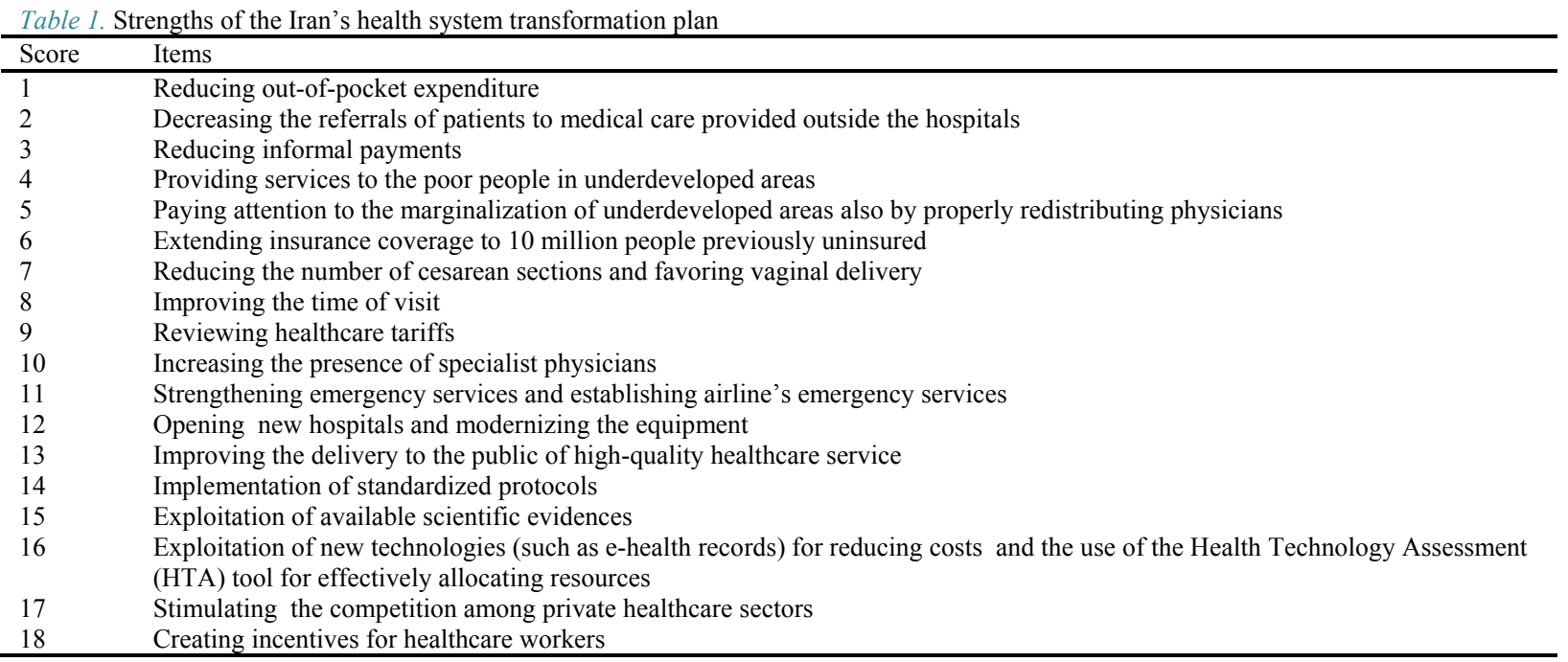


oped areas also by properly redistributing physicians, and providing services to the poor people, extending insurance coverage to 10 million people previously uninsured, as well as stimulating the competition among private healthcare sectors to increase the quality of healthcare services are other factors that can be considered strengths.

It is important to monitor and review all the pillars of the implementation of the plan, privileging a longitudinal oversight rather than a non-routine cross-sectional assessment.

\section{Weaknesses}

Weaknesses of Iran's health transformation plan (Table 2) are mainly represented by the insufficient attention to the proper inclusion of the family and continuity physicians as well as of PHC workers in the healthcare transformation plan, whilst imbalanced attention has been paid to specialized and super-specialized medical/surgical strains. Another weakness is given by the delay of the implementation of some sectors of the plan, like the tariff plan of nurses, the referral system, health promotion and prevention and healthcare service delivery to particularly vulnerable subjects such as children, women and the elderly. Different factors have contributed to such weaknesses, including the lack of implementation of the pilot project at a smaller scale, inappropriate and ineffective dialogue with insurances and private healthcare sectors, as well as with other stakeholders. In addition, increasing costs represent other weakness for Iran's healthcare transformation plan.

Iran's healthcare system is plagued by shortage of hospital beds and of health workforce (physicians, nurses, and other healthcare workers).
Iran has not paid enough attention to improve the attractiveness of its healthcare system, favoring and encouraging medical tourism, by exploiting the media and in particular the new information and communication technologies. The lack of strategic purchasing and allocation of financial resources with increasing debts towards pharmaceutical companies are further weaknesses of the system, together with employees' dissatisfaction with the government due to delays in payments, and the failure to fully implement policy processes at the light of evidence-based policy-making, with the consequent drought of properly standardized diagnostic and therapeutic guidelines and protocols. This last factor contributes to the possibility of increased medical errors and poor quality of care.

Further, it should be emphasized that in Iran, medicine is generally doctor-centered rather than patient-centered.

\section{Opportunities}

Many opportunities (Table 3) can be generated for improving Iran's healthcare system, such as supporting the leadership, paying more attention to the role of health in development of the country, implementing the MoHME as the most important organization in the field of healthcare, consolidating different insurance programs under the umbrella of national insurance system, opening health system decision-making process to the public, engaging more actively all stakeholders (both private and public) as well as the WHO and other international organisms, members of the clergy and religious people and attracting the views of political groups and influential personalities to support health transformation plan, such as members of the parliaments and representatives of different groups and strong political parties.

\begin{tabular}{|c|c|}
\hline Score & Items \\
\hline 1 & Delays in payments \\
\hline 2 & Lack of implementation of prevention and healthcare service delivery to particularly vulnerable subjects in high risk groups \\
\hline 3 & Imbalanced attention been paid to specialized and super-specialized medical/surgical strains \\
\hline 4 & Delay of the implementation of some sectors of the plan like the tariff plan of nurses \\
\hline 5 & Insufficient attention to the proper inclusion of the family and continuity physicians \\
\hline 6 & Insufficient attention to primary healthcare \\
\hline 7 & Lack of implementation of the pilot project at a smaller scale \\
\hline 8 & Inappropriate and ineffective dialogue with insurances and private healthcare sectors \\
\hline 9 & Increasing debts towards pharmaceutical companies \\
\hline 10 & Lack of strategic purchasing and allocation of financial resources \\
\hline 11 & Not enough attention been paid to improve encouraging medical tourism \\
\hline 12 & Failure to fully implement policy processes at the light of evidence-based policy making (EBM) \\
\hline Score & Items \\
\hline \multirow[t]{2}{*}{1} & Supporting the leadership \\
\hline & $\begin{array}{l}\text { Involving members of the clergy and religious people and attracting the views of political groups and influential personalities to } \\
\text { support health transformation plan }\end{array}$ \\
\hline \multirow[t]{2}{*}{2} & Paying more attention to the role of health in development of the country \\
\hline & Role of the Iranian parliament's legislative body to provide supportive laws for new funding \\
\hline \multirow[t]{3}{*}{3} & Implementing the MoHME as the most important organization in the field of healthcare \\
\hline & Increasing the amount of gross domestic product (GDP) \\
\hline & Increased revenue taxes \\
\hline 4 & Consolidating different insurances under the umbrella of national insurance system \\
\hline 5 & Opening health system decision making process to the public \\
\hline 6 & Engaging more actively all stakeholders \\
\hline 7 & Negotiation and constructive dialogue with planners and efforts to reduce opposition \\
\hline 8 & Increasing efficiency of health system \\
\hline 9 & Paying more attention to specific patients \\
\hline
\end{tabular}


From a political standpoint, support for the Iranian parliament's legislative body to provide supportive laws for new funding and its implementation and continuity should be searched. Moreover, negotiation and constructive dialogue with planners and efforts to reduce opposition should be pursued to improve health policy processes and to properly implement health priorities in the government.

Healthcare service provision should be improved by revising healthcare services package and increasing efficiency of healthcare system, paying more attention to specific patients, supporting more infertile couples, paying attention to various diagnostic levels and therapeutic services, as well as to health tourism.

From an economic-financial standpoint, increased revenue taxes, modification of health system payment to service providers and efforts in increasing the amount of gross domestic product (GDP) for health expenses, allocating at least $10 \%$ of subsidies to health sector represent other opportunities.

Finally, the support of national media for better disseminating and increasing the public awareness of the health promotion plan should be sought.

\section{Threats}

The major threat (Table 4) to Iran's health transformation plan is of economic-financial nature, especially considering the rate of inflation in Iran. Health system represents, indeed, a particular type of market, with a lack of competition between the different healthcare providers, an increasing demand and excessive expectations and a scarce oversight by non-health agencies concerning medical equipment prices.

Moreover, the funding and the provision of financial resources are characterized by a high degree of instability. Several factors contribute to this, including non-payment of financial liabilities by insurances and delay in payments from insurances to public hospitals as well as nonaggregation of insurance funds despite approved laws and failure to co-operate with insurers in increasing the package of services and accepting some obligations. Other economic issues are given by over-raising of tariffs for doctors.

Further threats are given by the dissatisfaction of some stakeholders in the health sector, a bad opinion concerning doctors and healthcare system in general created by misleading and inaccurate news. As such, it is an onus to make media aware of some health problems in order to disseminate reliable, not distorted information. Also political issues should be considered, in that political dissidents could depict some problems of the healthcare promotion plan much bigger than they actually are.

\section{Discussion}

SWOT analysis is quite popular for the evaluation of health programs and plans (9). It is an effective tool, indeed, in order to individuate health priorities and to suggest changes in health system reforms and involving all the stakeholders (10). Moreover, SWOT analysis has been successfully used for evaluating regional prevention plans in Italy (11), implemented using an innovative participatory approach, exploiting the new technologies and creating an online web-based community of practice. It has been used also in Malta (12) after the global financial and macroeconomic crisis of 2008/2009, as well as in Kosovo (13) about patients satisfaction with healthcare services, in Tanzania and Zambia (14) concerning the benefits coming from the global health initiatives (GHIs), in Rwanda (15) related to the implementation of the Universal Health Coverage (UHC), among others. The current analysis enabled us to individuate the main strengths, weaknesses, opportunities and threats of HSTP.

The healthcare system in Iran has performed significant health promotion activities over the past years, and health indicators have changed accordingly, in that health decision- and policy-makers are trying to make people healthier and achieve a satisfactory health level.

The government of President Rouhani began to implement HSTP, despite international sanctions which created numerous problems in various areas, including health. All countries in the world are looking for effective changes in their healthcare systems. The healthcare system is one of the most sophisticated systems, which has made access to justice and more efficient health services for people a major concern for healthcare providers (16). They have to face a rapid growth of technology in this sector, the changing nature of non-communicable diseases, aging populations, increasing health costs, various mechanisms of payment to service providers, increased access to healthcare services and request of better quality services. Reforms should take into account different dimensions and should have a broad and large view (17). Unplanned and unshared revisions can have a dangerous impact on the health sector, and, as such, efforts are wasted together with a large amount of funds, without reaching the goals (18). On the contrary, satisfaction of patients with health services is a good indicator for assessing the quality of the healthcare services delivered (19).

After completing the HSTP, several studies were conducted to assess the satisfaction of the patients about the healthcare services. These studies have been conducted in different parts of Iran. In a study conducted in Tehran, the authors compared the satisfaction of those who were referred before and after the HSTP. The results showed that,

\begin{tabular}{ll}
\hline Score & Items \\
\hline 1 & Instability of economic-financial nature of the health system \\
2 & Lack of competition between the different healthcare providers \\
3 & Non-payment of financial liabilities by insurances and delay in payments from insurances to public hospitals \\
4 & Non-aggregation of insurance funds \\
5 & Not sufficiently increasing the package of services and accepting some obligations \\
6 & Dissatisfaction of some stakeholders \\
\hline
\end{tabular}


after implementation of the HSTP, satisfaction with timely visits of doctors, as well as the observance of religious standards and ethics, the provision of pre-discharge training and the status of hospital rooms significantly changed (20). In another study, conducted in Mazandaran, the satisfaction level of 1,200 patients was examined and the results indicated that they were satisfied with the implementation of the HSTP and the services provided to them (21). In another study conducted in West Azerbaijan, Urmia, the results showed that $83.6 \%$ of the patients were satisfied with the services provided (22). In another study in Ilam, satisfaction with the HSTP from the viewpoint of patients and patients' companions was studied and most of the participants were satisfied with the HSTP (23). After implementation of the health system reform, effective and appropriate changes in the provision of services will be created, and providing better services to the people will make them more satisfied with the services (24).

One of the important tasks of the health sector is to provide conditions for the provision of UHC in its various dimensions to its community. UHC means providing a wide range of high-quality health services in the areas of promotion, prevention, treatment, rehabilitation and palliative care that everyone can benefit, without compromising finances (25). UHC provides everyone with access to health services focused on the most important causes of illness and death, and ensures that the quality of these services is high enough to improve the health of the patient. Public health coverage by protecting people from the financial implications of paying for health services from their pockets prevents them from poverty due to unexpected illnesses (26).

Achieving UHC is one of the world's most important points when agreeing on sustainable development goals in 2015, and is listed as the eighth target in the Sustainable Development Goals (SDGs), which refers to "good health and well-being". Countries that move to public health coverage are pursuing other health goals and other sustainable development objectives (27).

By implementing HSTP, decision- and policy-makers in Iran have taken effective steps to reach UHC. Lack of financial protection in health is known as a major issue affecting health systems. Unfortunately, due to increased health costs, many people who are not economically fit will in some cases avoid receiving health services and increase the illness burden associated with the disease for themselves and their families. Different countries in the world try to reduce the amount of pocket payments to provide health services, which increases the level of access to services for people and health equity. The health service delivery system should be both horizontal and vertical, and this is only possible when people are able to pay for health services and one way to achieve this is to reduce the amount of direct payments an individual performs for health services (28).

WHO has identified the protection system against unexpected/catastrophic expenditure of patients as one of the three main goals of the health system. Concerns about increasing health costs for people are of interest to health decision- and policy-makers in all countries (29).
Reducing direct out-of-pocket (OOP) to receive services is one of the key indicators that should be considered by decision- and policy-makers. One can safely say that one of the most important achievements of HSTP is to reduce the OOP for health services. The Iranian MoHME announced that with the implementation of HSTP the goal of decreasing the amount of OOP by $10 \%$ has been reached (30). Also in the case of special patients, HSTP has reduced the amount of OOP (31). Taken together, these results show the effectiveness of HSTP (32).

Maximum population coverage is one of the ways to reach the UHC. This, in addition to ensuring that all people receive services, will also bring decision- and policymakers closer to the goal of creating vertical justice in the health system. Of course, for some reasons, such as the government's impossibility to granting access to any people, coverage of the health service population cannot be as high as $100 \%$, but what is important is maximizing this parameter (33).

After implementation of HSTP, many people who previously did not have any insurance were covered by insurance services using government measures. This makes possible for people to be protected against costly health services. On one hand, due to the permanent restriction of health resources, as well as the augmented needs on the other hand, the need to prioritize coverage of more important, more effective, and more vital health services in the state-supported services category is an essential necessity. This is another key element of achieving UHC services, which is known as the "package of services". In fact, the package of services that the government provides for people should have features that address the basic needs of the people and promote health - and not just the centralized treatment. By implementing HSTP, health policy- and decision-makers have revised the package of health services. Increasing support for natural cesarean deliveries, supporting infertile couples, and implementing the benefit of urban margins to cover poor people for healthcare services are some of the goals of HSTP (30).

The issues mentioned above are some of the achievements of HSTP, but there are some problems that should be addressed by healthcare providers. Some dissatisfactions with health providers, such as physicians and nurses, as well as payment system problems, have caused them to undergo major changes in the financial field $(34,35)$.

The present analysis has a number of strengths, being based upon a systematic search of both the scholarly peerreviewed and of the gray literature. On the other hand, it has some limitations that should be properly acknowledged and mainly concern the choice of the sample of experts, in that a nonprobability sampling technique was used.

\section{Conclusion}

SWOT analysis is quite popular for the evaluation of healthcare programs and plans. It is an effective tool, indeed, in order to individuate health priorities and to suggest changes in health system reforms, involving all the stakeholders. The current analysis enabled us to individuate the main strengths, weaknesses, opportunities and 
threats of HSTP. In our study, 34 subjects expressed comments and suggestions. Based on their advice, the SWOT analysis of Iran's HSTP was revised, finalized and then implemented. From the present analysis, it has emerged that HSTP in Iran, like many of the initiatives that have been recently introduced and not fully implemented yet, has a wide range of challenges, difficulties and pitfalls that health decision- and policy-makers need to pay attention to. Interacting with criticisms, taking into account public opinion and strengthening the plan can make the project more effective, and it can be anticipated that, in the future, if fully planned and implemented, better conditions in the health sector in Iran will be achieved.

\section{Conflict of Interests}

The authors declare that they have no competing interests.

\section{References}

1. Han W. Health care system reforms in developing countries. J Public Health Res 2012; 1: 199-207.

2. World Health Organization. The World health report 2000: health systems: improving performance. 2000; Available from: http://www.who.int/whr/2000/en/.

3. Galárraga $\mathrm{O}$, Sosa-Rubí SG, Salinas-Rodríguez A, Sesma-Vázquez S. Health insurance for the poor: impact on catastrophic and out-ofpocket health expenditures in Mexico. Eur J Health Econ. 2010;11: 437-47.

4. Stokes J, Gurol-Urganci I, Hone T, Atun R. Effect of health system reforms in Turkey on user satisfaction. J Glob Health. 2015;5: 020403 .

5. Towse A, Mills A, Tangcharoensathien V. Learning from Thailand's health reforms. BMJ 2004; 328: 103-5.

6. Akinci F, Mollahaliloğlu S, Gürsöz H, Oğücü F. Assessment of the Turkish health care system reforms: a stakeholder analysis. Health Policy. 2012; 107: 21-30.

7. Laurell AC. Health system reform in Mexico: a critical review. Int J Health Serv. 2007:37:515-35.

8. Moradi-Lakeh M, Vosoogh-Moghaddam A. Health Sector Evolution Plan in Iran; Equity and Sustainability Concerns. Int J Health Policy Manag. 2015;4:637-40.

9. van Wijngaarden JD, Scholten GR, van Wijk KP. Strategic analysis for health care organizations: the suitability of the SWOT-analysis. Int J Health Plann Manage. 2012;27:34-49.

10. Jesus TS, Landry MD, Dussault G, Fronteira I. Human resources for health (and rehabilitation): Six Rehab-Workforce Challenges for the century. Hum Resour Health. 2017;15:8.

11. Giusti A, Perra A, Lombardo F. The experience of a nationwide Community of Practice to set up Regional Prevention Plans in Italy. Health Res Policy Syst. 2017;15:63.

12. Buttigieg SC, Schuetz M, Bezzina F. Value Chains of Public and Private Health-care Services in a Small EU Island State: A SWOT Analysis. Front Public Health. 2016;4:201.

13. Ramadani N, Zhjeqi V, Berisha M, Hoxha R, Gashi S, Begolli I, et al. Patients' satisfaction with health services at the national institute of public health of Kosova. Mater Sociomed. 2016;28:168-72.

14. Mwisongo A, Soumare AN, Nabyonga-Orem J. An analytical perspective of Global health initiatives in Tanzania and Zambia. BMC Health Serv Res. 2016;Suppl 4:223.

15. Nyandekwe M, Nzayirambaho M, Baptiste Kakoma J. Universal health coverage in Rwanda: dream or reality. Pan Afr Med J. 2014; 17:232.

16. Elias PEM, Amelia Cohn. Health Reform in Brazil: Lessons to Consider. Am J Public Health. 2003;93:44-8.

17. Tanik FA. Health-care reform in Turkey: far from perfect. Lancet. 2014:383:28.

18. Altenstetter C. Insights from health care in Germany. Am J Public Health. 2003;93:38-44.

19. Hone T, Gurol-Urganci I, Millett C, Bașara B, Akdağ R, Atun R. Effect of primary health care reforms in Turkey on health service utilization and user satisfaction. Health Policy Plan. 2017;32:57-67.

20. Hashemi B, Baratloo A, Forouzafar MM, Motamedi M, Tarkhorani M. Patient Satisfaction Before and After Executing Health Sector Evolution Plan. Iranjem. 2015;3:134-8.

21. Goudarzian A H, Sharif Nia H, Jafari H, Jamali S, Badiee M, Sayemi Z, et al. Inpatient Satisfaction with Health System Transformation Project in Mazandaran Educational Hospitals, Iran. J Mazandaran Univ Med Sci. 2016;26:190-5

22. Mousavi J, Mohaddesi H, Farhad N, Fathi AA. Evaluating satisfaction level among in-patients about the health system evolution program in affiliated hospitals of Urmia University of Medical Sciences. J Urmia Nurs Midwifery Fac. 2016;14:601-10.

23. Tavan H, Menati R, Alimardani O, Sayadi F, Borgi M. A survey on patients and patient' companion satisfaction for health reform plan in the Shahid Mostafa Khomeini hospital of Ilam city in 2015. NVJ. 2016;2:27-39.

24. Ali Jadoo SA, Aljunid SM, Sulku SN, Nur AM. Turkish health system reform from the people's perspective: a cross sectional study. BMC Health Serv Res. 2014;14.

25. Evans DB, Hsu J, Boerma T. Universal health coverage and universal access. Bull World Health Organ. 2013;91:546-A.

26. Vega J. Universal health coverage: the post-2015 development agenda. Lancet. 2013;381:179-80.

27. World Health Organization. Millennium Development Goals (MDGs). 2017; Available from: http://www.who.int/topics/ millennium development goals/en/.

28. Pace LE, Dusetzina SB, Fendrick AM, Keating NL, Dalton VK. The impact of out-of-pocket costs on the use of intrauterine contraception among women with employer-sponsored insurance. Med Care. 2013; 51:959-63.

29. World Health Organization. The world health report 2000 - Health systems: improving performance. 2000; Available from: http://www. who.int/whr/2000/en/.

30. Ministry of Health and Medical Education (MoHME). Health sector evolution. 2017; Available from: http://tahavol.behdasht.gov.ir

31. Sarkhanlou F, Saeedi M, Janbabai G, Nikfar S, Morteza-Semnani K, Zaboli P. Comparative Study of Direct Patient and Drug Costs before and after the Implication of Healthcare Reform Program in Sari, Iran J Mazandaran Univ Med Sci. 2016;26:228-32.

32. Piroozi B, Moradi G, Esmail Nasab N, Ghasri H, Farshadi S, Farhadifar F. Evaluating the effect of health sector evolution plan on cesarean rate and the average costs paid by mothers: A case study in Kurdistan province between 2013-2015. Hayat. 2016;22:245-54.

33. Marmot M. Universal health coverage and social determinants of health. Lancet. 2013;382:1227-8.

34. Nakhaei Z, Abdolreza Gharehbagh Z, Jalalmanesh S. A survey on Nurses' Satisfaction Concerning the Health System Reform Plan in Hospitals Affiliated to Birjand University of Medical Sciences in 2016. J Rafsanjsn Uin Med Sci. 2017:16:61-72.

35. Shariati A, Jamshidbeigi Y, Baraz pardnjati S, Haghighizadeh MH, Abbasi M. Assessment of nurses, patient satisfaction, patient attendants in educational hospitals in Ahvaz city health development plan in 2015. J Clin Nursi Midwife. 2017;6:9-18. 